\title{
A Cross Sectional Study of Medical Students' Perception of Their Educational Environment in Ghana
}

\author{
Temitope O. Ade-Oshifogun ${ }^{1}$, Jean A. Cadet $^{2} \&$ Jochebed B. Ade-Oshifogun $^{2}$ \\ ${ }^{1}$ Medical Doctor, University of Ghana, Accra, Ghana \\ ${ }^{2}$ Andrews University, Berrien Springs, Michigan, USA \\ Correspondence: Samuel P. Abraham, Associate Professor of Nursing, 1001 Bethel Circle, Bethel University \\ School of Nursing, Mishawaka, Indiana, USA. E-mail: samuel.abraham@betheluniversity.edu
}

Received: May 6, 2019

doi:10.20849/jed.v3i2.585
Accepted: May 27, 2019

Online Published: May 30, 2019

\begin{abstract}
Background: The quality of medical education is affected by many factors, one of which is the educational environment of medical education. However, there is paucity of studies addressing the educational environment from African medical schools. The aim of this study was to determine the clinical year students' perceptions of their educational environment at a medical school in Ghana. This was done with the goal of identifying factors that may impact positive changes in the school.
\end{abstract}

Methods: A cross-sectional study was undertaken using the DREEM questionnaire. The questionnaire was administered to students in clinical years $1,2, \& 3$ at the time of the study. 298 students participated in the study by convenience sampling. Data was analyzed using SPSS version 24 . The total score and the five subscales of DREEM scores were used in the final analysis.

Results: A total of 298 out of 300 students completed the questionnaire out of which Fifty six percent of respondents were male. There was no significant gender differences in the total DREEM scores $\left[F_{(1,274)}=1.019\right.$, $\mathrm{p}=0.314]$. The overall educational environment was positive $\mathrm{M}=117.32 \pm 15.45$. Areas for improvement were students' perception of the teachers $(26.09 \pm 3.59)$ and students' perception of the atmosphere $(25.71 \pm 5.62)$. The students' perception of learning $(30.70 \pm 5.20)$, and students' academic self-perceptions $(21.11 \pm 3.74)$ were positive. Students' social self-perceptions $(13.71 \pm 2.99)$ was neutral. There was no significant difference in perception by clinical year $\left[\mathrm{F}_{(2,274)}=0.298, \mathrm{p}=0.742\right]$.

Conclusion: The perception of students at this Ghanaian medical school can be described as positive and negative. The school should consider the two domains with negative perceptions as areas for improvement. Students reported problem-based learning as a preferred method of teaching versus the traditional method. Attention to the learning atmosphere and student-focused learning is likely to increase perception.

Keywords: medical students, educational environment, students' perception, DREEM, Africa, medical school

\section{Introduction}

The quality of medical education is affected by many factors, one of which is the environment of medical education. The medical school is best thought of as a 'learning environment' where reform initiatives are undertaken to shape the development of physicians in training. Researchers have attempted to identify and quantify the learning environment. It has been described as the climate, ethos, curriculum and culture of the institution (Hicks, Lin, Robertson, Robinson, \& Woodrow, 2001). The undergraduate curriculum in most medical schools in the developing world is still in the traditional mode where the focus is teacher-centered and less student-centered. This traditional mode ignores the fact that students are the main stakeholders of the medical school curriculum. Students' learning should be focused primarily by two fundamental questions: how teachers can effectively help students to achieve the learning objectives; and how learning can be sustained over a period of time (White et al., 2014). The answer to these fundamental questions results in outcome-based learning that is student focused.

Some students have the ability to learn despite the learning environment while other students are affected by the learning environment. Such effects can be positive or negative depending on the type of learning environment. Some medical school instructors utilize the teaching style learnt from their professors/teachers while others 
utilize student-centered teaching styles that focus on students' learning styles and students' ability to understand what is being taught. Therefore, instructor teaching style as a component of the learning environment may support or hinder the students' ability to learn.

Humiliation in classroom and/or clinical setting had been identified as a negative learning environment for medical students(Frank, Carrera, Stratton, Bickel, \& Nora, 2006). Frank 2006 also stated that such humiliation by classroom and clinical instructors was described as the 'hidden curriculum' where students are afraid to speak up in class or in clinic/ward because of the fear of being wrong and labeled as 'stupid or inadequately prepared.' It is unclear if the hidden curriculum plays a major role in students learning, though research supports its existence and the negative effect on learning (Hafferty, 1994). In developing countries where systematic evaluation of curriculum may be inconsistent, the medical students may not have regular opportunity to voice their satisfaction and/or dissatisfaction of the curriculum and other learning environmental factors. It is therefore important that the learning environment be evaluated to help improve learning.

The medical school studied employs a traditional educational system for the clinical years and a curriculum based on a teacher-centered approach. Students form study groups that are independent of the curriculum or instructors' teaching style. Students perceive learning as one-way transmission of information (from instructor to student). Learning is evaluated by students' final course examinations with limited feedback from the students.

A proven method of evaluating education or learning environment is to evaluate the students' perception of the environment. The Dundee Ready Educational environment Measure (DREEM) was developed by Roff et.al (2005) to measure the educational environment in health professional education programs. This tool was developed by an international Delphi panel of medical educators and it is a non-culturally specific instrument (Roff, 2005). It is applicable for use in Africa and other continents. It has been widely used in continents like Middle East, India, Europe, Australia, Asia and America (Bavdekar, Save, Pillai, \& Kasbe, 2019; Noreen, Khan, \& Nehra, 2018; Salih et al., 2018).

\section{Study Aims}

The objectives of this study are to:

- Explore the medical students' perception of their educational environment.

- Compare within clinical year differences in the medical students' perceptions.

- Compare within gender differences in the medical students' perception.

\section{Materials and Methods}

A cross-sectional study was conducted with medical students in Ghana. The study included clinical year students from 1 st, $2^{\text {nd }}$, and 3 rd year clinical rotations.

Dundee Ready Education Environment Measure (DREEM) questionnaire was utilized for data collection. Permission was sought and obtained for the use of the questionnaire. DREEM contains 50 items which are designed with a 5 point Likert-type scale ranging from strongly agree to strongly disagree with $0=$ strongly disagree, 1 = disagree, 2 = unsure, $3=$ agree, and $4=$ strongly agree (Roff, 2005). The DREEM questionnaire contains five subscales with a total score of 200 . There are five subscales with each subscale having individual scores for items on the subscale. There are nine items written in the negative; these items were re-coded and scored in the positive for consistent scoring. DREEM measures the perceptions of learning (PL - 12 items); perceptions of teaching (PT -11 items); academic self-perception (ASP - 8 items); perception of atmosphere (PA - 12 items); and social self-perception (SSP - 7 items). The DREEM instrument has internal consistency (alpha 0.89), overall fit of 0.76 (Hammond, O'Rourke, Kelly, Bennett, \& O'Flynn, 2012). It has been used in many countries including Nepal, Nigeria, and India (Bavdekar et al., 2019; Roff, McAleer, Ifere, \& Bhattacharya, 2001). Not only has it been used on medical students but it has also been used on nurses (Bakhshi, Azari, \& Bakhshaliabad, 2013). When used for a Ghanaian medical school, the internal consistency for the overall DREEM was 0.92 (Mogre \& Amalba, 2016).

DREEM gives a global score of 200 and the score can be used as a general measure. The results from DREEM can be considered at three levels - individual items, subscales and total overall DREEM scores. Individual items with a mean score of $\geq 3.5$ are considered very positive, $2-3$ scores are average and can be improved, and $\leq 2.0$ needs particular attention (Miles, Swift, \& Leinster, 2012). The raw scores for each item on the subscales are summed and averaged for each participant. The mean of these average scores are taken as the summary score for each subscale. The interpretation is similar to the individual scores. 
Consent was implied with survey completion. Study description and implied consent information were provided on the first page of the questionnaire. The survey was voluntary and anonymous to eliminate the fear of repercussion. This increased the motivation to participate. All clinical year medical students were approached for participation. Three hundred students volunteered to participate and 298 completed the questionnaire.

Completed questionnaire was scored and analyzed using SPSS Version 24. Demographic data was analyzed using descriptive statistics with means and standard deviations. Non-parametric one-way analysis of variance (ANOVA) was utilized to compare the means of the educational environment and its' subscales within clinical year and gender $(\mathrm{p}<0.05)$.

\section{Results}

298 out of 300 questionnaires were returned (99\%). Only 276 completed data on gender (92\%). Fifty six percent of participants were male students. Almost equal numbers of participants from each clinical year (Table 1). Fifty two percent of participants were between 20 and 24 years old.

Table 1. Demographic characteristics of study participants

\begin{tabular}{lll}
\hline Characteristics & & No. (\%) \\
\hline Gender & Male & $155(56.2)$ \\
& Female & $121(43.8)$ \\
Age (year) & $20-24$ & $152(52.2)$ \\
& $25-29$ & $119(40.9)$ \\
& $30-34$ & $18(6.2)$ \\
Clinical year & $40-44$ & $2(0.07)$ \\
& 1st clinical & $93(33.6)$ \\
& 2nd clinical & $91(32.9)$ \\
& 3rd clinical & $93(33.6)$ \\
\hline
\end{tabular}

The overall mean DREEM score was $121.0 \pm 17.28$, and gender did not make a difference in both the total score and the subscale scores (Table 2). There seem to be equal perception of the educational environment by both male and female medical students.

Table 2. Mean subscale and total Dundee Ready Educational Environment Measure (DREEM) scores by gender

\begin{tabular}{llc}
\hline Characteristics & Mean score \pm SD & P-value \\
\hline Perceptions of Learning & $31.05 \pm 5.29$ & \\
Male & $31.51 \pm 5.36$ & 0.266 \\
Female & $30.79 \pm 5.22$ & \\
Perceptions of Teachers & $27.60 \pm 4.26$ & \\
Male & $27.85 \pm 4.40$ & 0.526 \\
Female & $27.52 \pm 4.29$ & \\
Academic Self-Perceptions & $21.11 \pm 3.74$ & \\
Male & $21.41 \pm 3.40$ & 0.170 \\
Female & $20.78 \pm 4.19$ & \\
Perception of Atmosphere & $27.22 \pm 6.31$ & \\
Male & $27.63 \pm 6.66$ & 0.364
\end{tabular}




\begin{tabular}{lll} 
Female & $26.93 \pm 6.07$ & \\
Social Self Perceptions & $14.00 \pm 3.14$ & \\
Male & $13.98 \pm 3.28$ & 0.971 \\
Female & $13.97 \pm 2.90$ & \\
Total (Perception of educational & $121.00 \pm 17.28$ & \\
environment) & $122.38 \pm 16.96$ & 0.257 \\
Male & $119.98 \pm 17.90$ & \\
Female & \\
\hline
\end{tabular}

Table 3 represents the results of the total score by clinical year. There was no significant difference in mean total score by clinical year $\left(\mathrm{F}_{(2,274)}=0.546, \mathrm{p}=0.580\right)$. The maximum possible score was 200 . Students in each clinical year reported moderate scores across the board with little variation in scores. The global scores were similar across clinical years $1-3(121.72 \pm 16.93 ; 122.29 \pm 19.25 ; 119.73 \pm 16.08)$ and between genders $(122.38$ $\pm 16.96 ; 119.98 \pm 17.90)$. These scores revealed more positive than negative educational environment perception among the students. To fully identify the specific areas needing improvement, the subscales scores were calculated.

Table 3. Mean Dundee Ready Educational Environment Measure (DREEM) scores by domain and clinical year

\begin{tabular}{lllll}
\hline Characteristics & 1st Clinical & 2nd Clinical & 3rd Clinical & P-value \\
\hline Perceptions of Learning & $31.12 \pm 5.15$ & $31.21 \pm 5.36$ & $31.17 \pm 5.46$ & 0.992 \\
Perceptions of Teachers & $27.88 \pm 4.72$ & $27.73 \pm 4.60$ & $27.47 \pm 3.50$ & 0.808 \\
Academic Self-Perceptions & $21.58 \pm 3.96$ & $21.15 \pm 3.51$ & $20.66 \pm 3.80$ & 0.246 \\
Perception of Atmosphere & $27.19 \pm 5.96$ & $28.11 \pm 7.31$ & $26.58 \pm 5.87$ & $0.299^{*}$ \\
Social Self Perceptions & $13.95 \pm 2.95$ & $14.08 \pm 3.47$ & $13.84 \pm 2.96$ & 0.885 \\
Total (Education Environment) & $121.72 \pm 16.93$ & $122.29 \pm 19.25$ & $119.73 \pm 16.08$ & 0.580
\end{tabular}

*Since assumption of homogeneity of variance was violated for perception of atmosphere, the Welch test $\mathrm{p}$ value was reported here instead of the ANOVA p value

Table 4. Average scores of all items on the five domains of the Dundee Ready Educational Environment Measure (DREEM) from the study participants

\begin{tabular}{|c|c|c|c|c|c|}
\hline Domain Items & $\begin{array}{l}\text { Mean } \\
\text { score }\end{array}$ & $\begin{array}{l}\text { Standard } \\
\text { deviation }\end{array}$ & Domain Items & $\begin{array}{l}\text { Mean } \\
\text { score }\end{array}$ & $\begin{array}{l}\text { Standard } \\
\text { deviation }\end{array}$ \\
\hline \multicolumn{3}{|c|}{ Perceptions of Learning } & \multicolumn{3}{|c|}{ Academic Self-Perceptions } \\
\hline $\begin{array}{l}1 \text { I am encouraged to participate in } \\
\text { class }\end{array}$ & 2.87 & 0.84 & $\begin{array}{l}26 \text { Last year's work has prepped me } \\
\text { well for this year }\end{array}$ & 2.48 & 0.90 \\
\hline 7 Teaching is stimulating & 2.52 & 0.87 & 27 I am able to memorize all I need & 1.72 & 1.01 \\
\hline 13 Teaching is student centered & 2.31 & 0.99 & $\begin{array}{l}31 \text { Learned a lot about empathy in } \\
\text { my profession }\end{array}$ & 2.74 & 0.86 \\
\hline $\begin{array}{l}16 \text { Teaching is sufficiently } \\
\text { concerned to develop my } \\
\text { competence }\end{array}$ & 2.84 & 0.82 & $\begin{array}{l}41 \text { My problem-solving skills are } \\
\text { being well developed }\end{array}$ & 2.80 & 0.84 \\
\hline 20 teaching is well focused & 2.79 & 1.87 & $\begin{array}{l}45 \text { Much of what I have to learn } \\
\text { seems relevant to a career in } \\
\text { medicine }\end{array}$ & 3.02 & 0.72 \\
\hline
\end{tabular}


22 The teaching is sufficiently concerned to develop my confidence

24 Teaching time is put to good use

$2.71 \quad 0.74$

25 Teacher over-emphasizes factual

2.38

0.92 learning

38 I am clear about the learning objectives of the course

44 Atmosphere motivates me to be an active learner

47 Long term learning is emphasized over short term

48 The teaching is too teacher-centered

$2.73 \quad 0.85$

$2.69 \quad 0.87$

$2.66 \quad 0.96$

$1.98 \quad 1.02$

Sub-total score

31.05

5.29

\section{Perceptions of Teachers}

2 Knowledgeable teachers

$3.54 \quad 0.53$

6 Teachers are patient with patients

8 Teachers ridicule students

$2.69 \quad 0.85$

2.03

1.09

9 Teachers are authoritarian

$2.25 \quad 1.06$

18 Teachers have good communication skills with patients

29 Teachers are good at providing feedback

32 Teachers provide constructive criticism

37 The teacher gives clear examples

39 Teachers get angry in class

$2.06 \quad 1.29$

40 Teachers are well prepared for

2.94

0.62 class

49 The students irritate the teachers

Sub-total score

$2.07 \quad 1.11$

27.60

4.26

\section{Academic Self-Perceptions}

5 Learning strategies continue to 1.89 work for me

10 Confident about passing

3.57

1.11

0.59

2.95

21 I feel I am being well prepared

0.81
Sub-total score

21.11

3.74

\section{Perception of Atmosphere}

11 Relaxed atmosphere during ward 2.10

1.04 teaching

12 School is well timetabled

$2.23 \quad 1.22$

17 Cheating is a problem in this

$2.28 \quad 1.33$ school

23 The atmosphere is relaxed during $\quad 2.58 \quad 0.83$ lecturers

$\begin{array}{lll}30 & \text { Opportunities to develop } & 2.46\end{array}$

interpersonal skills

33 I feel comfortable in class socially

$2.77 \quad 0.74$

34 The atmosphere is relaxed during $\quad 2.41 \quad 0.97$ seminars/tutorials

35 Disappointing experience $\quad 2.06 \quad 2.13$

36 I am able to concentrate well $\quad 2.55 \quad 0.82$

42 Enjoyment outweighs the stress $\quad 1.25 \quad 1.08$ of studying medicine

43 Atmosphere motivates me as a $\quad 2.27 \quad 0.96$ learner

50 I feel able to ask the questions $\quad 2.30 \quad 1.01$ that I want

Sub-total score

$27.22 \quad 6.31$

\section{Social Self Perceptions}

3 Good support system for stressed $\quad 1.04$

0.95 students

4 Too tired to enjoy clinical year $\quad 2.19 \quad 1.06$

14 Rarely bored in this clinical year $\quad 1.75 \quad 1.02$

15 Good friends in this school $\quad 3.03 \quad 0.79$

19 Good social life $\quad 2.60 \quad 1.03$

28 I seldom feel lonely $\quad 2.16 \quad 1.11$

$46 \mathrm{My}$ accommodation is pleasant $\quad 1.31 \quad 1.26$

Sub-total score $\quad 14.00 \quad 3.14$ for my profession

The perception of learning subscale has a maximum score of 48. The mean scores were positive (31.05) but with no significant difference by gender (Table 2) or by clinical year (Table 3). The most rated item in the subscale 
was item 1 "I am encouraged to participate in class" (Table 4), and the least scoring item was item 48 "The teaching is too teacher-centered." Item 48 also scored low across gender and clinical years (Tables $5 \& 6$ ).

Students' perception of teacher's subscale has a maximum score of 44 . The mean score was 27.60 , and there were no significant differences by gender or by clinical year. Items scoring the least on the subscale was item 29; "Teachers are good at providing feedback." This item was equally low across gender and clinical years.

The student's academic self-perception's mean score was 21.11 out of possible 32 with no significant differences by gender or clinical year. The least scoring items on this subscale are item 5, 27; "Learning strategies continue to work for me;" "I am able to memorize all I need." Perception of the educational atmosphere subscale had a mean score of 27.22 out of possible 48. The least scoring items on the subscale included items 42 "Enjoyment outweighs the stress of studying medicine." This item also had a low score across gender and clinical years.

The mean Social self-perception score of $14.00 \pm 3.13$ had no significant difference between clinical group scores. The lowest scoring items included items 3, 14, 46; "Good support system for stressed students;" "Rarely bored in this clinical year;" and "My accommodation is pleasant." The scores were low across gender and clinical years' $1-3$ scores.

Table 5. Items needing improvement by clinical year (Mean score $\leq 2$ )

\begin{tabular}{|c|c|c|c|c|}
\hline & \multirow[t]{2}{*}{ Individual Item } & \multicolumn{3}{|c|}{ Clinical Year in School } \\
\hline & & $1^{\text {st }}$ Clinical & $\underline{2}^{\text {nd }}$ Clinical & $3^{\text {rd }}$ Clinical \\
\hline 3 & Good support system for stressed students & 1.0 & 1.2 & 0.9 \\
\hline 5 & Learning strategies continue to work for me & 2.0 & 1.8 & 1.9 \\
\hline 8 & Teachers ridicule students & 1.9 & 1.9 & 2.3 \\
\hline 14 & Rarely bored in this clinical year & 1.7 & 1.7 & 1.8 \\
\hline 27 & I am able to memorize all I need & 1.8 & 1.5 & 1.8 \\
\hline 29 & Teachers are good at providing feedback & 2.0 & 2.1 & 1.8 \\
\hline 35 & I found the experience disappointing & 2.0 & 2.2 & 2.0 \\
\hline 42 & Enjoyment outweighs the stress of studying medicine & 1.2 & 1.2 & 1.3 \\
\hline 46 & My accommodation is pleasant & 1.4 & 1.0 & 1.4 \\
\hline 48 & The teaching is too teacher-centered & 1.9 & 2.0 & 2.0 \\
\hline
\end{tabular}

Table 6. Items needing improvement by gender (Mean score $\leq 2)$

\begin{tabular}{rlll}
\hline & Individual Item & Male & Female \\
\hline 3 & Good support system for stressed students & 1.1 & 0.9 \\
5 & Learning strategies continue to work for me & 1.9 & 1.9 \\
8 & Teachers ridicule students & 2.1 & 1.9 \\
14 & Rarely bored in this clinical year & 1.7 & 1.8 \\
27 & I am able to memorize all I need & 1.8 & 1.6 \\
29 & Teachers are good at providing feedback & 1.9 & 2.0 \\
35 & I found the experience disappointing & 2.1 & 1.9 \\
39 & Teachers get angry in class & 2.2 & 1.9 \\
42 & Enjoyment outweighs the stress of studying medicine & 1.2 & 1.2 \\
46 & My accommodation is pleasant & 1.1 & 1.6 \\
48 & The teaching is too teacher-centered & 2.1 & 1.8 \\
50 & The students irritate the teachers & 2.0 & 2.2 \\
\hline
\end{tabular}


For this study, items with equal and less than 2.0 score out of 4.0 in two or three clinical groups are tagged as items below expectations and needing improvement. Table 5 represents these items. Table 6 represents items with equal and less than 2.0 score out of 4.0 in at least one gender. These items are below expectations and needing improvement. There are minimal differences in the items needing improvement by gender and clinical years. Only items 29 and 50 (teachers get angry in class; the students irritate the teachers) are specific to gender within the low scoring items, though there is no significant difference between the gender.

Table 7. Subscale interpretation score of the Dundee Ready Educational Environment Measure (DREEM) by clinical year $(\mathrm{n}=277)$

\begin{tabular}{|c|c|c|c|c|}
\hline \multirow{2}{*}{ Level of score within subscale } & \multicolumn{4}{|c|}{ Number of respondents, n (\%) } \\
\hline & 1st Clinical & 2nd Clinical & 3rd Clinical & Overall \\
\hline \multicolumn{5}{|l|}{ Students' perceptions of Learning } \\
\hline Very Poor & $0(0)$ & $0(0)$ & $0(0)$ & $0(0)$ \\
\hline Negatively viewed & $9(9.7)$ & $12(13.2)$ & $10(10.8)$ & $31(11.2)$ \\
\hline More Positive perception & $73(78.5)$ & $66(72.5)$ & $75(80.6)$ & $214(77.3)$ \\
\hline Teaching is highly perceived & $11(11.8)$ & $13(14.3)$ & $8(8.6)$ & $32(11.6)$ \\
\hline \multicolumn{5}{|l|}{ Students' perceptions of teachers } \\
\hline Abysmal & $0(0)$ & $0(0)$ & $0(0)$ & $0(0)$ \\
\hline In need of retraining & $7(7.5)$ & $10(11.0)$ & $6(6.5)$ & $23(8.3)$ \\
\hline Moving in the right direction & $75(80.6)$ & $71(78.0)$ & $82(88.2)$ & $228(82.3)$ \\
\hline Model course organizers & $11(11.8)$ & $10(11.0)$ & $5(5.4)$ & $26(9.4)$ \\
\hline \multicolumn{5}{|l|}{ Students' academic self-perceptions } \\
\hline Feelings of total failure & $0(0)$ & $1(1.1)$ & $0(0)$ & $1(0.4)$ \\
\hline Many negative aspects & $9(9.7)$ & $7(7.7)$ & $13(14.0)$ & $29(10.5)$ \\
\hline Feeling more on the positive side & $65(69.9)$ & $69(75.8)$ & $67(72.0)$ & $201(72.6)$ \\
\hline Confident & $19(20.4)$ & $14(15.4)$ & $13(14.0)$ & $46(16.6)$ \\
\hline \multicolumn{5}{|l|}{ Students' perception of atmosphere } \\
\hline A terrible environment & $1(1.1)$ & $1(1.1)$ & $0(0)$ & $2(0.7)$ \\
\hline $\begin{array}{l}\text { There are many issues which needs } \\
\text { changing }\end{array}$ & $29(31.2)$ & $25(27.5)$ & $27(29.0)$ & $81(29.2)$ \\
\hline A more positive attitude & $58(62.4)$ & $56(61.5)$ & $63(67.7)$ & $177(63.9)$ \\
\hline A good feeling over all & $5(5.4)$ & $9(9.9)$ & $3(3.2)$ & $17(6.1)$ \\
\hline \multicolumn{5}{|l|}{ Students' social self-perceptions } \\
\hline Miserable & $2(2.2)$ & $1(1.1)$ & $0(0)$ & $3(1.1)$ \\
\hline Not a nice place & $53(57.0)$ & $50(54.9)$ & $55(59.1)$ & $158(57.0)$ \\
\hline Not too bad & $38(40.9)$ & $37(40.7)$ & $37(39.8)$ & $112(40.4)$ \\
\hline Very good socially & $0(0)$ & $3(3.3)$ & $1(1.1)$ & $4(1.4)$ \\
\hline \multicolumn{5}{|l|}{$\begin{array}{l}\text { Total (Students' education } \\
\text { environment) }\end{array}$} \\
\hline Very Poor & $0(0)$ & $0(0)$ & $0(0)$ & $0(0)$ \\
\hline Plenty of Problem & $9(9.7)$ & $12(13.2)$ & $11(11.8)$ & $32(11.6)$ \\
\hline More Positive than Negative & $79(84.9)$ & $72(79.1)$ & $78(83.9)$ & $229(82.7)$ \\
\hline Excellent & $5(5.4)$ & $7(7.7)$ & $4(4.3)$ & $16(5.8)$ \\
\hline
\end{tabular}

Table 7 showed that most students considered their overall educational environment as more positive than negative (82.7\%). They perceived their learning experience as positive $(77.3 \%)$, the perception of their teachers as moving into the right direction $(82.3 \%)$, and their academic self-perception as being more on the positive side (72.3\%). Fifty seven percent of the students perceived their social environment (social self-perception) as "Not a nice place" and $1 \%$ perceived it as "miserable." The social self-perception was the only subscale with negative 
perception. Low scoring items in this subscale included items 3, 14, 46; "Good support system for stressed students;" "Rarely bored in this clinical year;" and "My accommodation is pleasant."

\section{Discussion}

This study considered the medical students' perception of their educational environment in a Ghanaian African setting. This was a final year project by the principal investigator before graduation. There was a good survey response rate among the population studied probably because of the need to support a fellow student to finish his project.

A global score of 121/200 showed that the students perceived their educational environment more positive than negative. The global score between the clinical years were very close and were very similar to that of a Nigerian medical school (Roff et al., 2001). A likely reason for this is that the Ghanaian and the Nigerian medical schools share similar characteristics of colonial (British) origin for their educational environment, such as teaching methodologies, techniques in learning and social life (Bleakley, Brice, \& Bligh, 2008). Therefore, the students may perceive the learning environment and teachers similarly. A study in India also had global scores that were more positive than negative (Kohli \& Dhaliwal, 2013). According to these authors, most institutions that run teacher-centered, traditional, discipline-based curricula report similar global scores. It is worth noting that the medial school in our study runs a teacher centered, traditional curricula. This is evident by the lower scoring items 5 "Learning strategies continue to work for me;" and 48 "The teaching is too teacher-centered;"

Another item with low score similar to the Nigerian study by Roff et.al (2001) was item 27 "I am able to memorize all I need." This emphasizes the use of memorization as a teaching/learning method in the medical school. Factual learning is probably driven by the pattern of formative and summative assessments that the students currently encounter (Kohli \& Dhaliwal, 2013). A student is required to know facts and very minute details to help him/her pass exams because 'that is the way things are done at the medical school.' We pose that a problem-based learning versus factual learning should be fostered in the medical school to improve learning. Learning should be student-focused instead of teacher-focused. When students are actively involved in learning, they build confidence in their abilities and their profession.

A comparison of the clinical year and gender data showed that the clinical years and gender did not make any difference in the students' perception of the educational environment. This finding is different from the results of the study in Pakistan with significant gender differences for the domain of social self-perception (Askari et al., 2018). While female students in the Pakistan study had higher scores for 'social self-perception' than male students; the gender scores were similar in our study. Though both male and female gender scored low on item 39 "Teachers get angry in class;" the male scores were slightly higher (2.2) than female (1.9). This may be explained my female sensitivity to emotional issues. It is worth noting that most items that scored low between clinical years also scored low for both gender except 'Learning strategies continue to work for me' which scored low for clinical years only. Two items - 'teachers get angry in class' and 'the students irritate the teachers' scored low for both gender but not for the clinical years.

The study showed low scores on some important teacher related items such as 'teachers ridicule students;' 'teachers are good at providing feedback' and 'the teaching is too teacher-centered.' This finding is similar to the study in India where the authors observed the problem areas to include authoritarian teachers, teachers getting angry and overly teacher-centered approach to learning (Askari et al., 2018).These should challenge the administrators to appraise the educational pedagogy used in the school and seek ways to improve students' perception of their teachers.

In summary, this study examined the perceptions of medical student in Ghana University about their educational environment and exploring the gender and clinical year differences in perception. Though some items of educational importance scored low in the study, the overall students' perception of their educational environment is more positive than negative. Because there were no significant differences in scores by clinical year and gender, the data showed some homogeneity of the educational environment and how it is perceived by the students. The school should examine the impact of the low scoring items for their impact on the students' learning and future perceptions.

\section{Conclusion}

The educational environment plays a vital role in producing competent medical doctors since it influences how, why, and what medical students learn. The study examined the clinical year students' perceptions of their educational environment at a medical school in Ghana. 
The overall educational environment at this medical school was positive. This study revealed areas of the educational climate needing improvement. Though clinical years and gender did not have a significant effect on the students' perception of their educational environment; analysis of individual items on the questionnaire revealed some significant findings related to the attitude of professors, students' social life, and teacher-centered curriculum. For improvement to be realized, it is necessary for the school to understand students' perception of their educational environment and take steps to improve on the identified areas that were less than adequate. Medical students' perceptions can affect their ability to learn, how they relate to colleagues and patients in their future practice. It was evident from the study that students prefer problem-based learning than traditional teaching. A quick move in this direction will significantly improve students' outcomes and perceptions at this school.

\section{References}

Askari, H., Mansoori, N., Saeed, M. Z., Riaz, K., Mukhtar, A., Rana, M. N., \& Mubeen, S. M. (2018). The Dundee Ready Education Environment Measure ( DREEM ): Perception of educational environment and its impact on academic performance of medical and pharmacy students. Ann Jinnah Sindh Med Uni, 4(2), 59-63.

Bakhshi, H., Azari, F., \& Bakhshaliabad, M. (2013). Nursing students' perceptions of their educational environment based on DREEM model in an Iranian university. Malaysian Journal of Medical Sciences, 20(4), 55-62.

Bavdekar, S., Save, S., Pillai, A., \& Kasbe, A. M. (2019, April). DREEM Study: students 'perceptions of learning environment in a medical college in Mumbai, India, 67, 50-54.

Bleakley, A., Brice, J., \& Bligh, J. (2008). Thinking the post-colonial in medical education. Medical Education, 42(3), 266-270. https://doi.org/10.1111/j.1365-2923.2007.02991.x

Frank, E., Carrera, J. S., Stratton, T., Bickel, J., \& Nora, L. M. (2006). Experiences of belittlement and harassment and their correlates among medical students in the United States: Longitudinal survey. British Medical Journal, 333(7570), 682-684. https://doi.org/10.1136/bmj.38924.722037.7C

Hafferty, F. W. (1994). The hidden curriculum, ethics teaching, and the structure of medical education. Academic Medicine, 23, 403-407.

Hammond, S. M., O’Rourke, M., Kelly, M., Bennett, D., \& O’Flynn, S. (2012). A psychometric appraisal of the DREEM. BMC Medical Education, 12(1). https://doi.org/10.1186/1472-6920-12-2

Hicks, L. K., Lin, Y., Robertson, D. W., Robinson, D. L., \& Woodrow, S. I. (2001, March). Understanding the clinical dilemmas that shape medical students ' ethical development: Questionnaire survey and focus group study sex differences in speed of emergence and quality of recovery after anaesthesia : cohort study. Bmj, $322,709-710$.

Kohli, V., \& Dhaliwal, U. (2013). Medical students' perception of the educational environment in a medical college in India: a cross-sectional study using the Dundee Ready Education Environment questionnaire. Journal of Educational Evaluation for Health Professions, 10, 5. https://doi.org/10.3352/jeehp.2013.10.5

Miles, S., Swift, L., \& Leinster, S. J. (2012). The Dundee Ready Education Environment Measure (DREEM): A review of its adoption and use. Medical Teacher, 34(9). https://doi.org/10.3109/0142159X.2012.668625

Mogre, V., \& Amalba, A. (2016). Psychometric properties of the dundee ready educational environment measure in a sample of Ghanaian medical students. Education for Health: Change in Learning and Practice, 29(1), 16-24. https://doi.org/10.4103/1357-6283.178921

Noreen, K., Khan, K. A., \& Nehra, R. A. (2018). Students' Perception of Learning Environment Using Dundee Ready Education Environment Measure (Dreem) Inventory. Pakistan Journal of Public Health, 8(2), 112-116. https://doi.org/10.32413/pjph.v8i2.154

Roff, S. (2005). The Dundee Ready Educational Environment Measure (DREEM) - A generic instrument for measuring students' perceptions of undergraduate health professions curricula. Medical Teacher, 27(4), 322-325. https://doi.org/10.1080/01421590500151054

Roff, S., McAleer, S., Ifere, O. S., \& Bhattacharya, S. (2001). A global diagnostic tool for measuring educational environment: Comparing Nigeria and Nepal. Medical Teacher, 23(4), 378-382. https://doi.org/10.1080/01421590120043080

Salih, K., Idris, M., Elfaki, O., Osman, N., Nour, S., Elsiddig, H., ... Elfakey, W. (2018). Measurement of the 
educational environment in MBBS teaching program, according to DREEM in College of Medicine, University of Bahri, Khartoum, Sudan. Advances in Medical Education and Practice, 9, 617-622. https://doi.org/10.2147/amep.s160218

White, C., Bradley, E., Martindale, J., Roy, P., Patel, K., Yoon, M., \& Worden, M. K. (2014). Why are medical students "checking out" of active learning in a new curriculum?. Medical Education, 48(3), 315-324. https://doi.org/10.1111/medu.12356

\section{Copyrights}

Copyright for this article is retained by the author(s), with first publication rights granted to the journal.

This is an open-access article distributed under the terms and conditions of the Creative Commons Attribution license (http://creativecommons.org/licenses/by/4.0/). 